\title{
Screen Time Increases Risk of Overweight and Obesity in Active and Inactive 9-Year-Old Irish Children: A Cross Sectional Analysis
}

\author{
Aoife Lane, Michael Harrison, and Niamh Murphy
}

\begin{abstract}
Background: Independent associations between screen time (ST)/physical activity (PA) and overweight (OW)/obesity have been demonstrated but little research exists on the role of ST among sufficiently active children. Purpose: To examine the combined influence of ST and PA on risk of OW/obesity in a nationally representative sample of 9-year-old Irish children. Methods: The sample in this cross sectional analysis contained 8568 children. Self-report parent data were used to group children into ST and PA categories and related to OW/obesity using forced entry logistic regression. Results: High ST ( $>3$ hours/day), bedroom TV and mobile phone ownership increased risk of OW/obesity in high and low active children $(P<.05)$. Low PA $(<9$ bouts fortnightly) was also associated with OW/obesity. In combined analyses, OW/obesity was lowest in the reference low ST/high PA group with ORs of 1.38, 1.63, and 2.07, respectively, in the low ST/low PA, high ST/high PA, and high ST/low PA groups. Access to electronic media, low socioeconomic status, parental obesity, and not engaging in sports were all related to high ST $(P<.05)$. Conclusion: This study supports findings that ST is associated with OW/Obesity demonstrating this separately in high and low active children.
\end{abstract}

Keywords: overweight/obesity

Ireland like many other developed nations is facing the challenge of tackling the rise in obesity, which is now evident in preadolescent children. The most recent International Health Behavior in School Children survey ${ }^{1}$ revealed that $14 \%$ of 11 -year-olds worldwide are overweight (OW) or obese. Rates are highest in the US at $26 \%$, lowest in the Netherlands at $6 \%$, and rates in Ireland are at $16 \%$. This data are self-report and likely to be a significant underestimate of true obesity. In fact, an earlier study using objective measures of weight and height ${ }^{2}$ reported that $27 \%$ of Irish 9-yearolds were OW/obese. There is evidence that weight patterns can be established from an early age ${ }^{3}$ and that children who are OW/obese are more likely to remain in these states into adulthood. ${ }^{4}$ Hence a focus on factors associated with OW/obesity in preadolescent children is justified.

Screen time (ST) and physical activity (PA) have both been widely studied as determinants of OW/obesity in children. Although earlier papers refer to the possibility of screen based pursuits displacing PA, ${ }^{5,6}$ the relationship between these behaviors is likely to be more complex. Others point to a very weak or no association between these behaviors and argue that children have sufficient time for both PA and screen-based leisure pursuits. ${ }^{7-9}$ Overall ST and TV viewing time is associated with obesity in preadolescent children in a number of cross-sectional studies $8,10,11$ and also predicts changes in body fat and obesity in a number of prospective studies. ${ }^{12-14}$ Importantly, these associations are independent of PA. The evidence for an inverse association between PA and OW/obesity in preadolescent children is not unanimous. Inverse associations are reported in some studies ${ }^{15-17}$ but not in many others. ${ }^{18-20}$

The authors are with the Dept of Health, Sport, and Exercise Science, Waterford Institute of Technology, Waterford, Ireland.
More recently there have been investigations into the joint associations of PA and ST in the development of OW/obesity in children, frequently using data collected from large-scale national surveys involving preadolescent and adolescent children. ${ }^{21-23}$ These all show the highest risk of OW/obesity in boys and girls with highest ST/lowest PA compared with the reference group of those with the lowest ST/highest PA, with other ST/activity combinations at intermediate risk. However, a key question, not adequately addressed, and critical for pediatric health priorities, is whether high $\mathrm{ST}$ is associated with OW/obesity in sufficiently active children. If not, resources might be better targeted at increasing both moderate and vigorous PA, rather than intervening to reduce ST. Ideally, this question should be addressed separately in preadolescent children, given the results of a recent study indicating the importance of ST for BMI in preadolescent children but PA for BMI in adolescents. ${ }^{3}$

The purpose of this analysis was therefore to examine the combined influence of ST and PA on risk of OW/obesity in a large nationally representative cohort of 9-year-old Irish school children, with particular reference to the risks of high ST in the most active of these children. A further aim of the analysis was to examine the correlates of high ST in this cohort.

\section{Methods}

\section{Design}

A detailed summary of the design, sampling, procedures, and instruments used in the study is available online (www.growingup.ie). ${ }^{24}$ Briefly, the Growing Up in Ireland study is a longitudinal study undertaken to describe the lives of Irish children. This includes understanding the many and varied influences on, and indicators of health and well being throughout childhood. Two nationally representative cohorts of children (infants and 9-year-olds) were 
recruited between 2007-2009. Baseline data from the older group $(n=8568)$ is the focus of this particular analysis. Follow up will be carried out after approximately 4 years.

\section{Participants}

The population for this research was 9-year-old children living in Ireland and their parents. A 2-stage sampling method was used; 910 schools were selected from a list of 3200 primary schools stratified according to region, disadvantaged status, denominational status, number of 9-year-olds and gender. In the second stage 9645 out of 17,054 families, who were randomly selected in the schools using random numbers, consented to participate representing a $57 \%$ response rate. Ethical approval was acquired from the Ethics Committee of the Health Research Board in Ireland. Consent was acquired from the principal of schools selected and subsequently from the parents/guardians of the children and the children themselves.

\section{Data Collection}

After a 4-stage piloting process to refine study procedures and instruments, ${ }^{25}$ appointments were made with participating households to collect data from the child and primary caregiver (usually the mother). Information was collected by trained interviewers using the CAPI (computer assisted personal interview) procedure.

\section{Instruments and Measures}

Questionnaires were drafted following consultation and piloting with research and health professionals and a children's advisory forum. The parental questionnaire was completed by the primary caregiver and was used as the main source of data for this analysis. Relevant data were all categorical in nature. Child's participation in hard exercise over a 2-week period was measured using a question adapted from the Leisure Time Exercise Questionnaire, which has good validity and reliability properties in relation to measuring PA. ${ }^{24}$ Data on time spent in leisure activities and activities undertaken with parents, which were collected using items from the UK Millennium Cohort Study and the Canadian National Longitudinal Survey of Children and Youth were also analyzed as were data on the presence of electronic equipment in the child's room, sport club membership, mobile phone ownership and social class (SC; SC1-2: highest SC, SC5-6: lowest SC). Data were also collected on frequency of intake (once, more than once, or not at all) of soft drinks and sugary foods in the last 24 hours. The height and weight of the primary caregiver and child were measured and recorded by the interviewer and used to derive BMI scores.

\section{Data Analysis}

Parents were characterized as normal $\left(<25 \mathrm{~kg} / \mathrm{m}^{2}\right)$ or OW/obese $\left(\geq 25 \mathrm{~kg} / \mathrm{m}^{2}\right)$. Children were similarly dichotomized using previously developed cut offs for this age group (males $<$ or $\geq 19.1$ and females $<$ or $\geq 19.07) .{ }^{26}$ Parental accounts of the number of days of participation in hard exercise in the past 2 weeks were used to categories children as engaging in low PA ( $0-8$ days) and high PA (9+ days). The latter was the last response option on the questionnaires and was deemed to most closely reflect participation in PA on most days, as per guidelines for children. Those who did not fall into this most active category were grouped together into 1 comparison group. Similarly, parental accounts of ST (watching TV/DVD/video) on an average weekday were used to create low
( $<3$ hours per day) and high ( $>3$ hours per day) ST categories. This definition of high ST was used, as the next response option of '1-3 hours per day' was not believed to reflect high ST. To assess the combined influence of these factors on OW/obesity, children were categorized into 1 of 4 ST/PA groups (Table 2). Chi squared statistics and forced entry logistic regression was used to identify factors associated with OW/obesity and with ST, using SPSS Version 17. Data were presented as adjusted odds ratios (OR) of the likelihood of specified outcomes (adjusted for potential confounding variables). Probability values and $95 \%$ confidence intervals for each adjusted OR were presented.

\section{Results}

Table 1 shows the characteristics of the sample. There was an even distribution of boys $(48.7 \%)$ and girls $(51.3 \%)$. Proportions in the different SC categories (SC1-2: 55.4\%, SC3-4: 35.5\%, SC5-6: 9.1\%) reflect those in the general Irish population for individuals aged less than 15 years. Overall, $21.5 \%$ of boys were OW/obese compared with $27.7 \%$ of girls $(P<.05)$. Obesity rates were also significantly $(P<.05)$ higher among the least affluent children. High ST was equally prevalent in boys and girls and was twice as common (13.9\% v $7.1 \%, P<.05)$ in the lowest $\mathrm{SC}$ group compared with the most affluent. Boys were more likely to be active $(P<.05)$ than girls and PA was not affected by SC. Finally, a greater proportion of girls and children from least affluent backgrounds were in the high ST/ low PA category.

Table 2 shows that sedentary indicators such as having a TV in the bedroom and owning a mobile phone were significantly related to $\mathrm{OW}$ and obesity regardless of activity status. Furthermore, there was evidence of a dose response relationship between ST and OW/ obesity. The lowest frequency of participation in hard exercise was associated with a greater risk of OW/obesity. Finally, regardless of activity status, girls and the least affluent were more likely to be OW and obese than boys and their more well off counterparts. Children with OW/obese parents were over twice as likely to be in a similar state.

The importance of 2 predictors of OW/obesity described in Table 2 differed across boys and girls. Firstly, the effect of ST was a little more pronounced in boys than girls. The ORs for $>3$ hours ST were 2.1 (95\% CI: 1.51-2.92) for boys and 1.5 (95\% CI: 1.13-2.05) for girls. For those who owned a mobile phone ORs were $1.58(95 \%$ CI: 1.30-1.89) for boys and 1.30 (95\% CI: 1.10-1.53) for girls.

Figure 1 shows the combined effect of PA and ST on OW and obesity. Compared with the reference group of low ST/high PA, children who reported low ST and low PA had a 38\% increased risk $(P<.05)$ of OW/obesity while children who maintained high PA but high ST had a $63 \%$ increased risk $(P<.05)$. Finally, children in the high ST/low PA category were twice as likely to be OW/obese $(\mathrm{OR}=2.07)$ than the reference group. While this last observation was similar across boys and girls, risk increased in boys as they went from low ST/low PA to high ST/high PA but not in girls where risk was similar in both of these categories.

The ORs for correlates of high ST ( $>3$ hours ST) in the overall group and also for high ST in high and low active children are displayed in Table 3. In the high active group, high ST was associated with low SC, nonmembership of a sports club, owning a mobile phone, having a TV and/or games console in the child's bedroom, watching TV with parents, and child/parental obesity. Many of the correlates of high ST in high active children (SC, parental obesity, mobile phone ownership, and watching TV with parents) were not significant in low active children. Playing with parents and having 
Table 1 Characteristics of Participants

\begin{tabular}{|c|c|c|c|c|c|c|}
\hline & & $\begin{array}{l}\text { Boys (\%) } \\
n=4024\end{array}$ & $\begin{array}{l}\text { Girls (\%) } n \\
=4242\end{array}$ & $\begin{array}{c}\text { SC1-2 }(\%) \\
n=4489\end{array}$ & $\begin{array}{c}\text { SC3-4 (\%) n } \\
=2882\end{array}$ & $\begin{array}{c}\text { SC5-6 (\%) } \\
n=739\end{array}$ \\
\hline \multirow[t]{3}{*}{ Child BMI } & Nonoverweight $(\mathrm{n}=5927)$ & 78.5 & 72.3 & 78.5 & 72.6 & 69 \\
\hline & Overweight $(\mathrm{n}=1494)$ & 16.7 & 21.2 & 17.8 & 20.1 & 21.7 \\
\hline & Obese $(n=446)$ & 4.8 & $6.5^{*}$ & 3.7 & 7.2 & $9.3^{* *}$ \\
\hline \multirow[t]{3}{*}{ Parental BMI } & Nonoverweight $(\mathrm{n}=3888)$ & 50.4 & 49.3 & 60.7 & 51.6 & 48.7 \\
\hline & Overweight $(\mathrm{n}=2605)$ & 32.5 & 32.6 & 28.5 & 31.2 & 30.6 \\
\hline & Obese $(n=1330)$ & 17.1 & 18 & 10.8 & 17.1 & $20.7 * *$ \\
\hline \multirow[t]{3}{*}{ Hard exercise (times $\mathrm{p} / 2 \mathrm{wks}$ ) } & $0-5$ times $(n=2135)$ & 19.9 & 29.6 & 22.4 & 27 & 29.3 \\
\hline & $6-8$ times $(n=1740)$ & 17.5 & 23.2 & 21.9 & 18.8 & 18.3 \\
\hline & $9+$ times $(n=4691)$ & 62.7 & $47.2^{*}$ & 55.7 & 54.2 & 52.5 \\
\hline Member of sports club & Yes $(n=6723)$ & 86.3 & $71 *$ & 83.9 & 75.8 & $68.3 * *$ \\
\hline Played outside with parents & Weekly $(n=6020)$ & 70.1 & 70.6 & 70 & 70.6 & 70.9 \\
\hline \multirow[t]{3}{*}{ Screen time per day } & None/less than $1 \mathrm{hr}(\mathrm{n}=2237)$ & 25.5 & 26.9 & 30.3 & 22.5 & 19.5 \\
\hline & $1-3 \mathrm{hrs}(\mathrm{n}=5543)$ & 65.2 & 64.1 & 62.7 & 67.1 & 66.6 \\
\hline & $3+\operatorname{hrs}(n=789)$ & 9.3 & 9.1 & 7.1 & 10.4 & $13.9 * *$ \\
\hline Mobile phone & Yes $(\mathrm{n}=3393)$ & 35.6 & $44.1 *$ & 32.3 & 45.9 & $52 * *$ \\
\hline TV in bedroom & Yes $(n=3205)$ & 39.2 & $35.5^{*}$ & 25.8 & 47.4 & $56.4 * *$ \\
\hline Computer in bedroom & Yes $(n=536)$ & 6.2 & 6.1 & 5.1 & 6.6 & $8.5 * *$ \\
\hline Games console in bedroom & Yes $(n=2612)$ & 38.2 & $22.7 *$ & 24 & 35.9 & $40.8^{* *}$ \\
\hline Watched TV with parents & Yes $(\mathrm{n}=7533)$ & 88.2 & 88.8 & 86.5 & 91.1 & $90.3 * *$ \\
\hline \multirow[t]{4}{*}{ Combined categories } & Low ST/High PA $(n=4368)$ & 58.3 & 44 & 52.9 & 49.6 & 46.3 \\
\hline & Low ST/Low PA $(\mathrm{n}=3410)$ & 32.4 & 47 & 40.1 & 40 & 39.8 \\
\hline & High ST/High PA (323) & 4.4 & 3.2 & 2.8 & 4.5 & 6.2 \\
\hline & High ST/Low PA $(n=465)$ & 4.9 & $5.9 *$ & 4.3 & 5.9 & $7.7 * *$ \\
\hline
\end{tabular}

$* P<.05$ Boys v Girls; ** $P<.05$ SC1-2 v SC3-4 v SC5-6.

Abbreviations: SC, social class.

a computer in a bedroom were significant $(P<.05)$ correlates in the low active group.

\section{Discussion}

The novel finding in this analysis is that ST of $>3$ hours per day and easy access to screen-based technologies is related to OW/ obesity in preadolescent Irish children, including the children with the highest frequency of hard PA. A dose response relationship was evident between levels of ST and likelihood of OW/obesity with the availability of screen-based technologies associated with high ST. This study reinforces findings in previous research ${ }^{8,10-14}$ that have demonstrated ST and TV viewing to be associated with indices of body weight, independent of PA status and justifies efforts to reduce ST and access to screen-based technologies as part of pediatric public health initiatives.

Analysis of independent associations with OW/obesity indicates that the association between ST and OW/obesity was apparent even in the most active children in this study $(9+$ bouts of hard exercise over 2 weeks). ORs for high ST and having a TV in the bedroom for OW/obesity were of similar magnitude in high and low active children. The importance of ST is also evident in the graded associations of the combined analysis. Increasing levels of ST was associated with increased likelihood of OW/obesity regardless of PA level. Furthermore with an OR of 1.38 for low ST/low activity and an OR of 1.63 for high ST/high activity, it appears that increases in frequency of hard exercise does not prevent an increase in the likelihood of OW/obesity as the child increases ST. ST needs to be kept to a minimum regardless of participation in hard exercise. The combined effect of ST and PA may differ slightly between boys and girls however. Among girls there was minimal difference in the risk for OW/obesity between the low ST/low PA $(\mathrm{OR}=1.45)$ and high $\mathrm{ST} /$ high PA $(\mathrm{OR}=1.56)$ combined categories. This suggests that the increasing levels of ST did not have an effect on the likelihood of OW/obesity in girls as long as PA also increased. This putative gender difference requires confirmation in future studies.

There is a dearth of studies in the literature examining the combined effects of PA and ST on OW/obesity in preadolescent children. In one previous study of 7- to 12 -year-olds ${ }^{23}$ high ST and low PA increased the likelihood of OW/obesity 3- to 4-fold compared with the reference category of low ST and high PA. The magnitude of this combined effect is slightly greater than in the current study, possibly because of more objective measurements of PA. Unlike the current study however, the intermediate categories were not significantly different from the reference group, possibly because of the small sample size. One other study ${ }^{22}$ involving preadolescents and adolescents showed graded associations of ST and PA with OW/obesity that were similar to those observed in the current study. However neither of these studies demonstrated an increased likelihood of OW/obesity in the most active children. 
Table 2 Correlates of Overweight/Obesity

\begin{tabular}{|c|c|c|c|c|}
\hline & & $\begin{array}{c}\text { Overall sample adjusted OR } \\
(95 \% \mathrm{Cl}) \mathrm{n}=7035\end{array}$ & $\begin{array}{c}\text { High PA adjusted OR } \\
(95 \% \mathrm{Cl}) \mathrm{n}=3860\end{array}$ & $\begin{array}{c}\text { Low PA adjusted OR } \\
(95 \% \mathrm{Cl}) \mathrm{n}=3175\end{array}$ \\
\hline \multirow[t]{2}{*}{ Gender } & Boys & 1 & 1 & 1 \\
\hline & Girls & $1.41(1.25-1.60)^{\wedge}$ & $1.30(1.09-1.55)^{\wedge}$ & $1.51(1.27-1.80)^{\wedge}$ \\
\hline \multirow[t]{3}{*}{ Social class } & SC1-2 & 1 & 1 & 1 \\
\hline & SC3-4 & $1.18(1.04-1.34)^{\wedge}$ & $1.24(1.03-1.48)^{\wedge}$ & $1.11(.93-1.33)$ \\
\hline & SC5-6 & $1.33(1.089-1.62)^{\wedge}$ & $1.26(.94-1.68)$ & $1.39(1.05-1.85)^{\wedge}$ \\
\hline \multirow[t]{2}{*}{ Parent BMI } & Nonoverweight & 1 & 1 & 1 \\
\hline & OW/Obese & $2.14(1.90-2.42)^{\wedge}$ & $2.24(1.89-2.65)^{\wedge}$ & $2.07(1.75-2.44)^{\wedge}$ \\
\hline \multirow[t]{2}{*}{ Sports club } & Yes & 1 & 1 & 1 \\
\hline & No & $.99(.86-1.15)$ & $1.13(.90-1.41)$ & $.91(.75-1.10)$ \\
\hline \multirow[t]{3}{*}{ Hard exercise (times per $2 \mathrm{wks}$ ) } & $9+$ times & 1 & $\mathrm{n} / \mathrm{a}$ & $\mathrm{n} / \mathrm{a}$ \\
\hline & $6-8$ times & $1.25(1.08-1.45)^{\wedge}$ & & \\
\hline & $0-5$ times & $1.52(1.33-1.74)^{\wedge}$ & & \\
\hline \multirow[t]{3}{*}{ Screen time per day } & None/less than $1 \mathrm{hr}$ & 1 & 1 & 1 \\
\hline & $1-3 \mathrm{hrs}$ & $1.18(1.04-1.38)^{\wedge}$ & $1.16(.96-1.41)$ & $1.21(.99-1.50)$ \\
\hline & $3+\mathrm{hrs}$ & $1.78(1.43-2.22)^{\wedge}$ & $1.78(1.29-2.47)^{\wedge}$ & $1.77(1.31-2.39)^{\wedge}$ \\
\hline \multirow[t]{2}{*}{ TV in bedroom } & No & 1 & 1 & 1 \\
\hline & Yes & $1.38(1.19-1.59)^{\wedge}$ & $1.32(1.07-1.61)^{\wedge}$ & $1.45(1.19-1.77)^{\wedge}$ \\
\hline \multirow[t]{2}{*}{ Computer in bedroom } & No & 1 & 1 & 1 \\
\hline & Yes & $1.07(.84-1.36)$ & $1.23(.88-1.72)$ & $.91(.65-1.29)$ \\
\hline \multirow[t]{2}{*}{ Games console in bedroom } & No & 1 & 1 & 1 \\
\hline & Yes & $.89(.77-1.03)$ & $.88(.71-1.08)$ & $.91(.74-1.12)$ \\
\hline \multirow[t]{2}{*}{ Mobile phone } & No & 1 & 1 & 1 \\
\hline & Yes & $1.41(1.24-1.59)^{\wedge}$ & $1.56(1.31-1.86)^{\wedge}$ & $1.26(1.06-1.50)^{\wedge}$ \\
\hline \multirow[t]{4}{*}{ Combined categories } & Low ST/High PA & 1 & & \\
\hline & Low ST/Low PA & $1.38(1.22-1.56)^{\wedge}$ & & \\
\hline & High ST/High PA & $1.63(1.23-2.18)^{\wedge}$ & & \\
\hline & High ST/Low PA & $2.07(1.62-2.66)^{\wedge}$ & & \\
\hline
\end{tabular}

Note. OR adjusted for gender, social class, parent BMI, child height, sweet food/soft drink intake.

$\wedge \mathrm{OR}$ is significant $(P<.05)$.

PA was also clearly associated with OW/obesity in the current study with the likelihood of OW/obesity increasing with decreasing frequency of hard exercise. Compared with those who undertook 9 bouts or more of hard exercise fortnightly, the OR of those who undertook $0-5$ bouts only was 1.52 . The OR for high (vs low) ST was slightly higher at 1.78 . In the combined analyses, decreasing frequency of hard exercise was associated with greater likelihood of OW/obesity in boys and girls who had low ST and high ST. It seems both high ST and low PA contribute independently to an increased likelihood of OW/obesity. Data from this analysis also suggests that during childhood, ST may have more of an influence on weight than PA. This supports claims that sedentarism predicts BMI to a greater extent than PA during the ages of 6 to 10 years. ${ }^{3}$ Thereafter, the role of PA may become more dominant, ${ }^{3,27}$ which reinforces the need to examine these associations separately in preadolescent and adolescent children. Some studies have demonstrated a relationship between poor dietary behaviors and TV viewing in children. ${ }^{29,30}$ However, the association with high ST in the current study was also independent of sweet food and soft drink intake. The mechanism by which high ST increases likelihood of OW/obesity is therefore unclear.
In this analysis, there was also evidence of a dose response relationship between ST and OW/obesity. Corresponding ORs increased to 1.18 for $1-3$ hours of ST per day $(P<.05)$ to 1.78 for $3+$ hours $(P<.05)$. In 2001, the American Academy of Pediatrics ${ }^{31}$ proposed a recommendation of no more than 2 hours per day of media time for children, which was largely based on concerns about the effect of TV viewing on issues such as aggressive behavior and self-image but did mention the initial discussions at that time about the link between sedentarism and obesity. Subsequent knowledge gains in this area, particularly in relation to the deleterious effects of increasing sedentarism, have led to the acceptance of this cut off point ( 2 hours daily) for children and adults. Canada was the first country to adopt this recommendation and produce national sedentary behavior guideline ${ }^{32}$ while the UK have included sedentary behavior in their most recent PA guidelines for young people. ${ }^{33}$ Based on this analysis of Irish children, it may be incumbent on relevant bodies to consider a similar strategy, as 3 hours ST/day is clearly 'too much' in the context of OW/obesity.

With ST established as a risk factor for OW/obesity in this cohort, the data from this study can provide valuable insights into the 


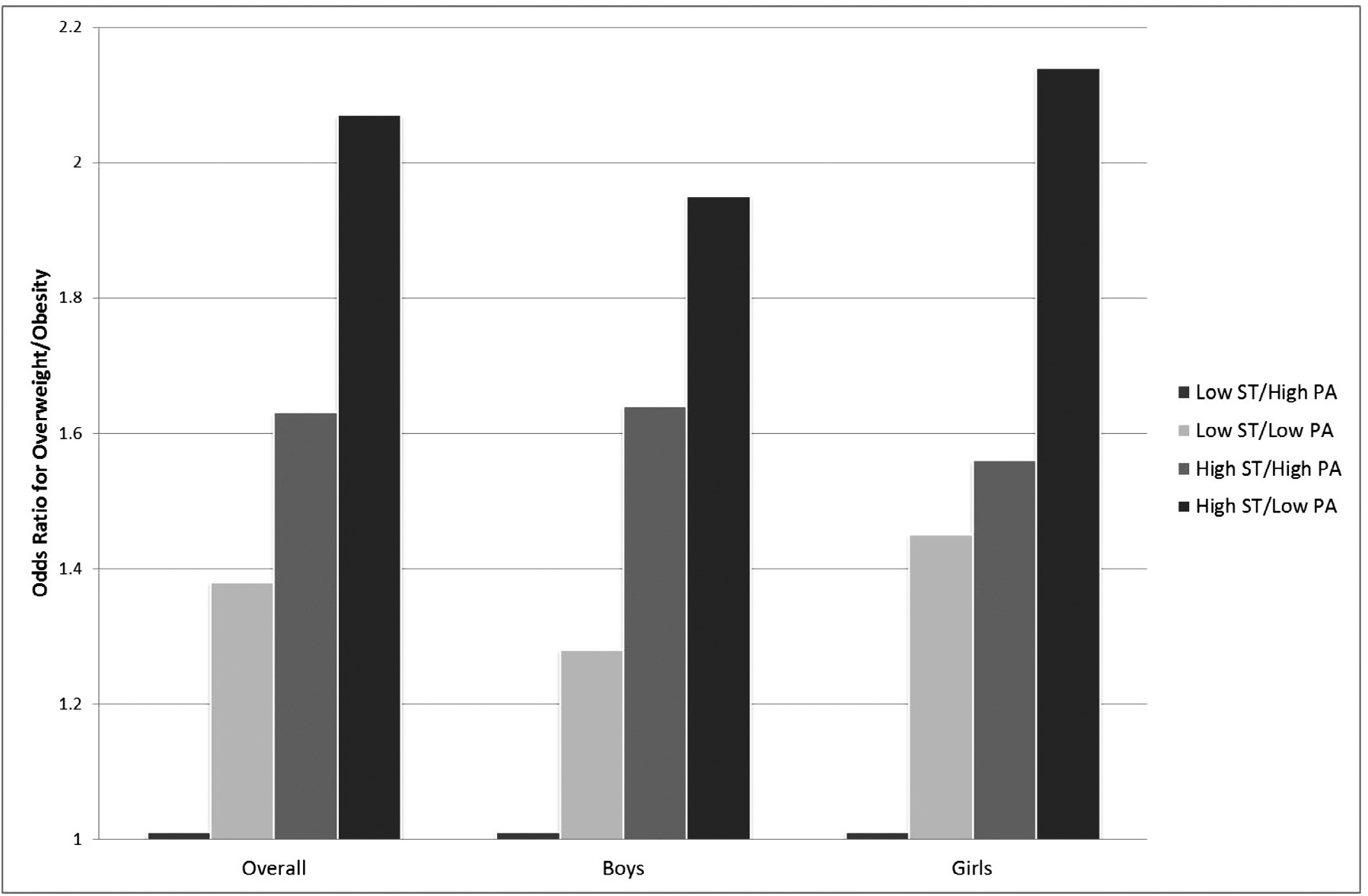

Figure 1 - Combined role of physical activity and screen time as predictors of overweight/obesity for overall sample, and boys and girls. OR adjusted for social class, parent BMI, child height, sweet food/soft drink intake. $*=\mathrm{OR}$ is significant $(P<.05)$ compared with reference category.

predictors of ST. As noted elsewhere ${ }^{28,29}$ decreasing social class was a predictor of ST with a gradient evident and less affluent children were more likely to have TVs in their bedrooms. Independent of social class, sedentary technology in the bedroom was significantly related to high ST among high and low active children. In a review of literature on the correlates of TV viewing it was also found that having a TV in the bedroom was related to TV viewing. ${ }^{29}$ The complex associations of social class, sedentary technology and ST warrant further investigation. Mobile phone ownership was also associated with OW/obesity and similar to previous findings ${ }^{29,30}$ parental TV viewing with children was related to ST among the high active children. Factors related to PA such as being a member of a sports club as well as playing outside with parents were related to ST, the latter among least active children only. Current understanding of the predictors of sedentarism remains some way behind that for $\mathrm{PA}^{34}$ so this analysis is an important contribution to the related evidence base; it appears that 'gadget' children who engage in sedentary rather than active leisure activities particularly with their parents are more likely to report high ST and have an unhealthy weight.

\section{Limitations}

The study was cross sectional thus no causal relationships could be identified and it is not clear if ST leads to weight gain or if excess weight causes children to favor sedentary pursuits. In this analysis high ST predicted OW/obesity and OW/obesity predicted high ST. Furthermore the nature of the data collected restricted the analysis somewhat. The categorical data on PA and ST behaviors did not permit the categorization of children into meeting and not meeting ST or PA guidelines using the 2-hour ST criteria and 60 minutes of moderate intensity per day. Despite this, analysis still revealed associations between PA, ST and OW/obesity. Not all of the questions used to collect the sedentary data were derived from previously validated measures and the data were largely self-report, which can lead to recall and social desirability bias. Finally, data on child behavior were collected from parents, however this is suggested for children aged less than $12^{35}$ and prompt cards were used to assist their understanding and improve the accuracy of responses.

\section{Conclusion and Recommendations}

Among this cohort of Irish 9-year-olds, ST was significantly related to weight, in high as well as low active children. Further investigation of the relationship between sedentarism and fatness over time is warranted ${ }^{36,37}$ and follow up data on these children will permit this additional analysis. The large sample size in this analysis facilitated a relatively unique investigation of correlates of high ST among high and low active children. In accordance with the independent influence of ST on indicators of health, some predictors of high ST are consistent across high and low active children. In conclusion, it remains important to promote participation in PA to prevent weight gain and separately, to tackle the factors (mobile 
Table 3 Correlates of High Screen Time in the Overall Group and in High and Low Active Children

\begin{tabular}{|c|c|c|c|c|}
\hline & & $\begin{array}{c}\text { High ST adjusted } \\
\text { OR }(95 \% \mathrm{Cl}) \mathrm{n}=7039\end{array}$ & $\begin{array}{c}\text { High ST/High PA adjusted } \\
\text { OR }(95 \% \text { Cl) } n=3861\end{array}$ & $\begin{array}{c}\text { High ST/Low PA adjusted } \\
\text { OR }(95 \% \mathrm{Cl}) \mathrm{n}=3178\end{array}$ \\
\hline \multirow[t]{2}{*}{ Gender } & Boys & 1 & 1 & 1 \\
\hline & Girls & $.87(.73-1.04)$ & $.89(.68-1.17)$ & $.84(.67-1.07)$ \\
\hline \multirow[t]{3}{*}{ Social class } & SC1-2 & 1 & 1 & 1 \\
\hline & SC3-4 & $1.15(.96-1.39)$ & $1.26(.95-1.68)$ & $1.07(.83-1.37)$ \\
\hline & SC5-6 & $1.40(1.07-1.84)^{\wedge}$ & $1.52(1.00-2.30)^{\wedge}$ & $1.32(.92-1.9)$ \\
\hline \multirow[t]{2}{*}{$\mathrm{TV}$ in room } & Yes & 1 & 1 & 1 \\
\hline & No & $1.38(1.12-1.69)^{\wedge}$ & $1.62(1.23-2.14)^{\wedge}$ & $1.48(1.14-1.93)^{\wedge}$ \\
\hline \multirow[t]{2}{*}{ Computer in room } & No & 1 & 1 & 1 \\
\hline & Yes & $1.48(1.10-1.99)^{\wedge}$ & $1.32(.84-2.08)$ & $1.60(1.08-2.38)^{\wedge}$ \\
\hline \multirow[t]{2}{*}{ Games console in room } & No & 1 & 1 & 1 \\
\hline & Yes & $1.43(1.17-1.75)^{\wedge}$ & $1.77(1.30-2.41)^{\wedge}$ & $1.23(.94-1.61)$ \\
\hline \multirow[t]{2}{*}{ Mobile phone } & No & 1 & 1 & 1 \\
\hline & Yes & $1.23(1.02-1.47)^{\wedge}$ & $1.41(1.07-1.86)^{\wedge}$ & $1.11(.88-1.42)$ \\
\hline \multirow[t]{2}{*}{ Sports club } & Yes & 1 & 1 & 1 \\
\hline & No & $1.38(1.13-1.68)^{\wedge}$ & $1.42(1.03-1.95)^{\wedge}$ & $1.31(1.02-1.68)^{\wedge}$ \\
\hline \multirow[t]{2}{*}{ Watched TV with parents } & No & 1 & 1 & 1 \\
\hline & Yes & $1.55(1.13-2.13)^{\wedge}$ & $2.20(1.24-3.9)^{\wedge}$ & $1.34(.91-1.96)$ \\
\hline \multirow[t]{2}{*}{ Played outside with parents } & Yes & 1 & 1 & 1 \\
\hline & No & $1.39(1.16-1.66)^{\wedge}$ & $1.22(.93-1.61)$ & $1.52(1.20-1.91)^{\wedge}$ \\
\hline \multirow[t]{2}{*}{ Parent BMI } & Nonoverweight & 1 & 1 & 1 \\
\hline & OW/Obese & $1.27(1.06-1.51)^{\wedge}$ & $1.40(1.07-1.82)^{\wedge}$ & $1.17(.92-1.48)$ \\
\hline \multirow[t]{2}{*}{ Child BMI } & Nonoverweight & 1 & 1 & 1 \\
\hline & OW/Obese & $1.54(1.28-1.85)^{\wedge}$ & $1.60(1.20-2.11)^{\wedge}$ & $1.49(1.17-1.89)^{\wedge}$ \\
\hline
\end{tabular}

Note. OR adjusted for gender, social class, parent, child BMI.

$\wedge$ OR is significant $(P<.05)$.

phones, TVs in bedrooms, non participation in sport and excessive weight) that appear to be conducive to participation in sedentary behaviors such as screen time.

\section{References}

1. Currie $\mathrm{C}$, Nic Gabhainn $\mathrm{S}$, Godeau $\mathrm{E}$, et al, eds. Inequalities in young people's health: HBSC International Report from the 2005/2006 Survey. Denmark: World Health Organisation; 2008.

2. Whelton H, Harrington J, Crowley E, Kelleher V, Cronin M, Perry IJ. Prevalence of overweight and obesity on the island of Ireland: results from the North South Survey of Children's Height, Weight and Body Mass Index, 2002. BMC Public Health. 2007;7:187. PubMed doi:10.1186/1471-2458-7-187

3. Hands BP, Chivers PT, Parker HE, Beilin L, Kendall G, Larkin D. The associations between physical activity, screen time and weight from 6 to 14 years: The Raine Study. J Sci Med Sport. 2011;14(5):397-403. PubMed

4. Viner RM, Cole TJ. Adult socioeconomic, educational, social, and psychological outcomes of childhood obesity: a national birth cohort study. BMJ. 2005;330(7504):1354. PubMed

5. Mutz DC, Roberts DF, Van Vuuren DO. Reconsidering the displacement hypothesis: television's influence on children's time use. Communic Res. 1993;20:51. doi:10.1177/009365093020001003
6. Epstein LH, Roemmich JN. Reducing sedentary behavior: role in modifying physical activity. Exerc Sport Sci Rev. 2001;29:103-108. PubMed doi:10.1097/00003677-200107000-00003

7. Marshall SJ, Biddle SJH, Sallis JF, McKenzie TL, Conway TL. Clustering of sedentary behaviours and physical activity among youth: a cross-national study. Pediatr Exerc Sci. 2002;14:401-417.

8. Ekelund U, Brage S, Froberg K, et al. TV viewing and physical activity are independently associated with metabolic risk in children: The European Youth Heart Study. PLoS Med. 2006;3(12):e488. PubMed

9. Anderson SE, Economous CD, Must A. Active play and screen time in US children aged 4 to 11 years in relation to sociodemographic and weight status characteristics: a nationally representative crosssectional analysis. BMC Public Health. 2008;8:366. PubMed

10. Andersen RE, Crespo CJ, Bartlett SJ, Cheskin LJ, Pratt M. Relationship of physical activity and television watching with body weight and level of fatness among children. JAMA. 1998;279(12):638-642. PubMed doi:10.1001/jama.279.12.938

11. Dowda M, Ainsworth BE, Addy CL, Saunders R, Riner W. Environmental influences, physical activity and weight status in 8-16 year olds. Arch Pediatr Adolesc Med. 2001;155:711-717. PubMed doi:10.1001/ archpedi.155.6.711

12. Berkey CS, Rockett HRH, Gillman MW, Colditz GA. One-year changes in activity and in inactivity among 10- to 15 -year-old boys and girls: relationship to change in body mass index. Pediatrics. 2003;111(4):836-843. PubMed doi:10.1542/peds.111.4.836 
13. Hancox RJ, Milne BJ, Poulton R. Association between child and adolescent television viewing and adult health: a longitudinal birth cohort study. Lancet. 2004;364:257-262. PubMed doi:10.1016/S01406736(04)16675-0

14. Jago R, Baranowski T, Baranowski JC, Thompson D, Greaves KA. BMI from 3-6 y of age is predicted by TV viewing and physical activity, not diet. Int J Obes. 2005;29:557-564. PubMed doi:10.1038/ sj.ijo.0802969

15. Ortega FB, Ruiz JR, Sjöström M. Physical activity, overweight and central adiposity in Swedish children and adolescents: the European Youth Heart Study. Int J Behav Nut Phys Act. 2007;19;4:61.

16. Tahna T, Wollmer P, Thorsson O, et al. Lack of physical activity in young children is related to higher composite risk factor score for cardiovascular disease. Acta Paediatr. 2011;100:717-721. PubMed doi:10.1111/j.1651-2227.2011.02226.x

17. Ekelund U, Luan J, Sherar LB, Esliger DW, Griew P, Cooper A. Moderate to vigorous physical activity and sedentary time and cardiometabolic risk factors in children and adolescents. JAMA. 2012;307(7):704-712. PubMed doi:10.1001/jama.2012.156

18. Maffeis $C$, Talamini G, Tato L. Influence of diet, physical activity and parents' obesity on children's adiposity: a four-year longitudinal study. Int J Obes Relat Metab Disord. 1998;22:758-764. PubMed doi:10.1038/sj.ijo.0800655

19. Bogaert N, Steinbeck KS, Baur LA, Brock K, Bermingham MA. Food, activity and family-environmental vs biochemical predictors of weight gain in children. Eur J Clin Nutr. 2003;57:1242-1249. PubMed doi:10.1038/sj.ejcn.1601677

20. Burke V, Beilin LJ, Simmer K, et al. Predictors of body mass index and associations with cardiovascular risk factors in Australian children: a prospective cohort study. Int J Obes Relat Metab Disord. 2005;29:15-23. PubMed doi:10.1038/sj.ijo.0802750

21. Eisenmann JC, Bartee RT, Smith DT, Welk GJ, Fu Q. Combined influence of physical activity and television viewing on the risk of overweight in US youth. Int J Obes. 2008;32:613-618. PubMed doi:10.1038/sj.ijo.0803800

22. Sisson SB, Broyles ST, Baker BL, Katzmarzyk P. Screen time, physical activity, and overweight in US youth: National Survey of Children's Health 2003. J Adoles Health; 2010:309-311.

23. Laurson KR, Eisenmann JC, Welk GJ, Wickel EE, Gentile DA, Walsh DA. Combined influence of screen time and physical activity recommendations on childhood overweight. J Paediatr. 2008;153:209-214. PubMed doi:10.1016/j.jpeds.2008.02.042

24. Murray A, McCrory C, Thornton M, et al. Growing up in Ireland: design, instrumentation and procedures for the child cohort. Dublin, Ireland: Department of Health and Children; 2011.
25. Williams J, McCrory C. Growing up in Ireland: report on pre-piloting, piloting and dress rehearsal phases of the project. Dublin, Ireland: Department of Health and Children; 2011.

26. Cole TJ, Bellizzi MC, Flegal KM, Dietz WH. Establishing a standard definition for child overweight and obesity worldwide: international survey. BMJ. 2000;320:1240. PubMed doi:10.1136/ bmj.320.7244.1240

27. Must A, Tybor DJ. Physical activity and sedentary behavior: a review of longitudinal studies of weight and adiposity in youth. Int J Obes. 2005;29:S84-S96. PubMed doi:10.1038/sj.ijo.0803064

28. Fairclough SJ, Boddy LM, Hackett AF, Stratton G. Associations between children's socioeconomic status, weight status, and sex, with screen based sedentary behaviours and sport participation. Int J Paediatr Ob. 2009;4:299-305. PubMed doi:10.3109/17477160902811215

29. Gorely T, Marshall SJ, Biddle SJH. Couch kids: correlates of television viewing among youth. Int J Behav Med. 2004;11(3):152-163. PubMed doi:10.1207/s15327558ijbm1103_4

30. Hardy LL, Baur LA, Garnett SP, et al. Family and home correlates of television viewing in 12-13 year old adolescents: the Nepean study. Int J Behav Nutr Phys Act. 2006;3:24. PubMed doi:10.1186/14795868-3-24

31. American Academy of Pediatrics. Children, adolescents and television. Pediatrics. 2001;107(2):423-426. PubMed doi:10.1542/ peds.107.2.423

32. Tremblay MS, LeBlanc AG, Janssen I, et al. Canadian sedentary behavior guidelines for children and youth. Appl Physiol Nutr Metab. 2011;36(1):65-71. doi:10.1139/H11-013

33. UK Department of Health. Physical Activity Guidelines for Children and Young People. UK: Crown Copyright; 2011.

34. Uijtdewilligen L, Nauta J, Singh AS, et al. Determinants of physical activity and sedentary behavior in young people: a review and quality synthesis of prospective studies. Br J Sports Med. 2011;45:896-905. PubMed doi:10.1136/bjsports-2011-090197

35. Sithole F, Veugelers, PJ. Parent and child's report of physical activity. Stat Canada Health Reports. 2008; 19(3).

36. Altenburg TM, Singh AS, van Mechelen W, Brug J, Chinapaw MJ. Direction of the association between body fatness and self reported screen time in Dutch adolescents. Int J Behav Nut Phys Act. 2012; 9(4).

37. Chinapaw MJM, Proper KI, Brug J, van Mechelen W, Singh AS. Relationship between young people's sedentary behavior and biomedical health indicators: a systematic review of prospective studies. Obes Rev. 2011;12:e621-e632. PubMed doi:10.1111/j.1467-789X.2011.00865.x 